\title{
Distorted Gravity: The Intensive and Extensive Margins of International Trade
}

\author{
By THOMAS CHANEY*
}

By considering a model with identical firms, Paul Krugman (1980) predicts that a higher elasticity of substitution between goods magnifies the impact of trade barriers on trade flows. In this paper, I introduce firm heterogeneity in a simple model of international trade. When the distribution of productivity across firms is Pareto, which is close to the observed size distribution of US firms, the predictions of the Krugman model with representative firms are overturned: the impact of trade barriers on trade flows is dampened by the elasticity of substitution, and not magnified.

In Krugman (1980), identical countries trade differentiated goods despite the presence of trade barriers because consumers have a preference for variety. If goods are less substitutable, consumers are willing to buy foreign varieties even at a higher cost, and trade barriers have little impact on bilateral trade flows. Total exports from country $A$ to country $B$ are given by the following expression:

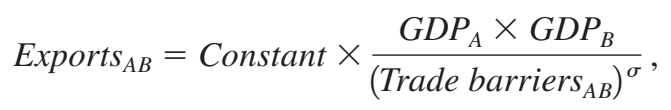

where $\sigma$ is the elasticity of substitution between varieties. A crucial assumption in this model is that all firms are identical, and that the only form of transportation cost is a variable cost. Under these assumptions, every firm exports to every country in the world. Trade barriers have a strong impact on trade flows when the elasticity of substitution between goods is high. Competition is fierce when the elasticity of substitution is high, and any cost disadvantage translates into large losses of market share.

In this paper, I add firm heterogeneity in productivity, as well as fixed costs of exporting. These simple amendments introduce a new margin of adjustment: the extensive margin. When transportation costs vary, not only does each exporter change the size of its exports (the intensive margin), but the set of exporters varies as well (the extensive margin). The main finding of this paper is that the elasticity of substitution has opposite effects on each margin. A higher elasticity makes the intensive margin more sensitive to changes in trade barriers, whereas it makes the extensive margin less sensitive. The reason is the following. When trade barriers decrease, new and less productive firms enter the export market. When the elasticity of substitution is high, a low productivity is a severe disadvantage. These less productive firms can capture only a small market share. The impact of those new entrants on aggregate trade is small. On the other hand, when the elasticity is low, each firm is sheltered from competition. The new entrants capture a

\footnotetext{
* Chaney: Department of Economics, University of Chicago, 1126 East 59th Street, Chicago, IL 60637 (e-mail: tchaney@uchicago.edu). I am grateful to Xavier Gabaix, Marc Melitz, and Daron Acemoglu for their encouragement and advice. I also thank the editor, three anonymous referees, and Richard Rogerson for their comments. For their suggestions and comments, I also wish to thank Sylvain Chassang, Sam Kortum, David Sraer, and participants at the Federal Reserve Board of Governors, Boston College, Boston University, Columbia University, University of Chicago, Chicago GSB, Harvard University, INSEAD, LSE, MIT, the New York Fed, New York University, University of Pennsylvania, University of California-Berkeley, University of California-San Diego, University of WisconsinMadison, the World Bank, and on the REStud Tour 2005. All remaining errors are mine.
} 
large market share. The impact of those new entrants on aggregate trade is large. So a higher elasticity of substitution magnifies the sensitivity of the intensive margin to changes in trade barriers, whereas it dampens the sensitivity of the extensive margin.

Which effect dominates? I prove that when the distribution of productivity across firms is Pareto, which is a good approximation of the observed distribution of US firms, ${ }^{1}$ the effect on the extensive margin dominates. My augmented model predicts that total exports from country $A$ to country $B$ are given by the following expression:

$$
\text { Exports } \left.\left._{A B}=\text { Constant } \times \frac{G D P_{A} \times G D P_{B}}{(\text { Trade barriers }}\right)_{A B}\right)^{\varepsilon(\sigma)} \text { with } \varepsilon^{\prime}(\sigma)<0 .
$$

The elasticity of aggregate trade with respect to trade barriers (both variable and fixed), $\varepsilon$, is negatively related to the elasticity of substitution, $\sigma$. Variable trade barriers enter the gravity equation with an exponent that depends only on the distribution of productivity and not on the elasticity of substitution, and fixed trade barriers with an exponent that is inversely related to the elasticity of substitution.

The model with heterogeneous firms also predicts that the same trade barriers will have a larger impact on trade flows than in the model with representative firms. When trade barriers decrease, each firm exports more. In addition, new firms start exporting. This adjustment on the extensive margin is quantitatively important. Given the observed distribution of firm size in the United States, I predict that the elasticity of trade flows with respect to variable trade barriers such as tariffs is twice as large as it would be in the absence of firm heterogeneity.

The prediction, that the effect of trade barriers on trade flows is magnified by the elasticity of substitution, is not specific to Krugman's model of trade. Maurice Obstfeld and Kenneth Rogoff (2001), for example, explain the six major puzzles in International Macroeconomics by the existence of trade barriers. The simple model they spell out to illustrate how plausible values for trade barriers can have a large impact on trade flows relies on the magnification by the elasticity of substitution. James E. Anderson (1979) presents a theoretical foundation for the gravity equation based on the Armington assumption of competitive trade in goods differentiated by country of origin. In both models, a higher elasticity of substitution will magnify the effect of trade barriers on trade flows, even in the absence of increasing returns or monopolistic competition.

The main contribution of this paper is to introduce the extensive margin of trade in a simple and tractable model with multiple countries and asymmetric trade barriers. The elasticity of aggregate trade flows with respect to trade barriers is larger than what traditional models would predict. It is not equal to the elasticity of substitution; it is inversely related to the elasticity of substitution.

In the remainder of this section, I review previous work related to this model, and existing empirical evidence that supports the predictions of this model.

Marc Melitz (2003) introduces firm heterogeneity in a general equilibrium model of international trade. I expand Melitz's model in the following way. I consider a world with many asymmetric countries, separated by asymmetric trade barriers. I then study the strategic choice of firms to export or not, and if they export, which countries to target. I embed my model in a global equilibrium. Such a model generates predictions for the structure of bilateral trade flows. I can pin down which firm from which country is able to enter a given market, and how it is affected by competition from local and other foreign firms, even in the presence of asymmetric bilateral trade barriers. The presence of fixed costs associated with entering foreign markets provides a simple foundation for the extensive margin of trade.

\footnotetext{
${ }^{1}$ See Erzo G. J. Luttmer (2007) for the most recent evidence, and this introduction for further references.
} 
Elhanan Helpman, Melitz, and Yona Rubinstein (forthcoming) develop a similar extension to the Melitz model with multiple countries. Using bounded support for the productivity shocks, they can make use of the information contained in the zeros of the trade matrices and improve on the traditional gravity regressions. They do not, however, generate analytical solutions for the extensive margin of trade. This gives them more flexibility in estimating empirically the probability that exporters enter a given foreign market. But it prevents them from deriving precise predictions for the role of variable and fixed costs in explaining both the intensive and the extensive margins of international trade.

Kim J. Ruhl (2005) builds a dynamic version of the Melitz model to explain the so-called elasticity puzzle. He argues that in response to high frequency transitory shocks, most of the adjustments of exports happen at the intensive margin, whereas in response to permanent shocks such as trade liberalization, both the intensive and the extensive margins adjust. I abstract from any dynamic considerations and build a model of the steady-state trade flows between many countries. Costas Arkolakis (2007) offers an extension to the current model to explain the existence of small exporters, even in the presence of fixed trade barriers. He proposes that firms can decide what fraction of a market they want to access, where the fixed entry cost increases with the number of consumers reached.

Jonathan Eaton, Sam Kortum, and Francis Kramarz (2007) find that the current model provides a good description of firm-level trade using data on French exporters. Among others, the current model predicts correctly many of the patterns of entry of heterogeneous firms into different markets, and the relationship between the size of a firm on its domestic market, and the number of foreign markets it enters. The assumption that productivity shocks are Pareto distributed provides a good fit for the firm-level data: it describes precisely the distribution of firm size within France, as well as which foreign markets a given firm enters.

There is wide empirical evidence that the Pareto distribution is a good approximation of the upper tail of the distribution of firm sizes. Since exporters are overwhelmingly large firms, and therefore in the upper tail of the size distribution, this distribution is a good candidate for a theoretical model of firm selection into export markets. Herbert A. Simon and Charles P. Bonini (1958) first noted that the size distribution of firm sizes is well described by a Pareto distribution. Recent evidence on this empirical regularity for the United States include Robert L. Axtell (2001) and Luttmer (2007). Xavier Gabaix (2008) provides a survey on the prevalence of "power law" distributions for firms in the United States and in Europe. Helpman, Melitz, and Stephen Yeaple (2004) estimate a Pareto distribution for both US and European firms to predict foreign direct investment in different sectors.

The closest evidence in support of the predictions of the current model are James E. Rauch (1999), Martin Andersson (2007), Matthieu Crozet and Pamina Koenig (2007), and Koenig (2005). Rauch finds that trade barriers have a milder impact on trade volumes for goods that are more homogenous. He defines homogenous goods as goods that are traded on organized exchanges, or goods that have a reference price. He argues that acquiring information about differentiated goods is costly, so that effectively differentiated goods face a higher trade barrier. This reasoning can, however, explain why there should be more trade in homogenous goods, but not why given trade barriers should have a bigger impact. The current model offers an alternative explanation for the interaction between product differentiation and trade barriers. I spell out a clear theoretical channel through which product differentiation affects trade barriers. Andersson (2007) uses firm-level export data on Swedish firms. He separates out the impact of variable trade barriers and the impact of fixed trade barriers (proxied by measures of "familiarity" of markets), and separates out their impact on the intensive and extensive margins of trade. First, he finds that fixed costs have a larger impact on the extensive margin than on the intensive margin of trade. Moreover, the impact of fixed trade barriers on the extensive margin is larger 
for differentiated goods than for homogenous goods. ${ }^{2}$ Crozet and Koenig (2007) use firm-level export data on French firms to structurally estimate the current model. The panel dimension of the data allows them to separate out the distance elasticity of trade costs from the elasticity of exports with respect to trade barriers. Koenig (2005) uses the same firm-level export data on French firms. As the current model predicts, she finds that the distance elasticity of individual firm exports (the intensive margin) is larger in sectors where goods are more homogenous, whereas the distance elasticity of the number of firms (the extensive margin) is smaller in sectors where goods are more homogenous. In addition, she finds that the share of exports explained by the extensive margin is larger in sectors with more differentiated goods. At the aggregate level, unlike the predictions of this model, she finds that in sectors with homogenous goods, the distance elasticity of total exports is mildly larger than in sectors with differentiated goods, but this difference is not significant.

Finally, several authors have stressed the quantitative importance of the extensive margin in explaining aggregate trade flows. David Hummels and Peter J. Klenow (2005) find that larger and wealthier countries trade more, and that 60 percent of the difference in aggregate trade flows comes from differences in the number of goods traded. Along a slightly different line, Kei-Mu Yi (2003) argues that the increase in trade in intermediate goods, which amounts to trade in more goods, can help explain the observed increase in international trade in the last decades. All find a strong response of the extensive margin to changes in trade barriers or country size that are consistent with the current model.

The remainder of the paper is organized as follows. Section I introduces a simple model of international trade with heterogeneous firms and derives partial equilibrium results. In Section II, I compute the general equilibrium of the world economy. Finally, Section III identifies separately the adjustments of the intensive and the extensive margins of trade, in response to changes in both variable and fixed trade barriers.

\section{Setup}

In this section, I introduce the basic ingredients of the model. I define preferences and technologies, and I characterize the optimal strategies of both firms and consumers in partial equilibrium.

There are $N$ potentially asymmetric countries that produce goods using only labor. Country $n$ has a population $L_{n}$. Consumers in each country maximize utility derived from the consumption of goods from $H+1$ sectors. Sector 0 provides a single homogenous good. The other $H$ sectors are made of a continuum of differentiated goods. If a consumer consumes $q_{o}$ units of good 0 , and $q_{h}(\omega)$ units of each variety $\omega$ of good $h$, for all varieties in the set $\Omega_{h}$ (determined in equilibrium), she gets a utility $U$,

$$
U \equiv q_{o}^{\mu_{0}} \prod_{h=1}^{H}\left(\int_{\Omega_{h}} q_{h}(\omega)^{\left(\sigma_{h}-1\right) / \sigma_{h}} d \omega\right)^{\left[\sigma_{h} /\left(\sigma_{h}-1\right)\right] \mu_{h}}
$$

where $\mu_{0}+\sum_{h=1}^{H} \mu_{h}=1$, and where $\sigma_{h}>1$ is the elasticity of substitution between two varieties of good $h$. I assume that $H>1$ so that I can compare sectors characterized by different degrees of product substitutability. ${ }^{3}$

\footnotetext{
${ }^{2}$ The impact of distance is also larger, which suggests that distance proxies for both variable and some fixed costs.

${ }^{3}$ It is empirically more relevant to compare sectors with different degrees of product substitutability than to compare different economies.
} 
Trade Barriers and Technology.-The homogenous good 0 is freely traded and is used as the numeraire. It is produced under constant returns to scale with one unit of labor in country $n$ producing $w_{n}$ units of good 0 . Its price is set equal to 1 so that if country $n$ produces this good, the wage in country $n$ is $w_{n}$. I shall consider only equilibria where every country produces some of the numeraire. ${ }^{4}$ This assumption greatly simplifies the analysis. It allows countries to differ both in size $\left(L_{n}\right)$ and in productivity $\left(w_{n}\right)$. There are two types of trade barriers, a variable and a fixed cost. The variable cost takes the form of an "iceberg" transportation cost. If one unit of any differentiated good $h$ is shipped from country $i$ to country $j$, only a fraction $1 / \tau_{i j}^{h}$ arrives. The rest melts on the way. The higher $\tau$, the higher the variable trade cost. ${ }^{5}$ In addition, if a firm from country $i$ in sector $h$ exports to country $j$, it must pay a fixed cost $f_{i j}^{h}$, in units of the numeraire.

All countries have access to the same technology. Due to the presence of fixed costs, firms in the differentiated sectors operate under increasing returns-to-scale technology. Each firm in sector $h$ draws a random unit labor productivity $\varphi$. The cost of producing $q$ units of a good and selling them in country $j$ for a firm with productivity $\varphi$ is

$$
c_{i j}^{h}(q)=\frac{w_{i} \tau_{i j}^{h}}{\varphi} q+f_{i j}^{h} .
$$

Firms are price setters. Given that demand functions are isoelastic, the optimal price charged in country $j$ by firm $\varphi$ from country $i$ is a constant mark-up over the unit cost (including transportation costs): $p_{i j}^{h}(\varphi)=\sigma_{h} /\left(\sigma_{h}-1\right) \times w_{i} \tau_{i j}^{h} / \varphi$.

As in Helpman, Melitz, and Yeaple (2004), I assume that productivity shocks are drawn from a Pareto distribution with shape parameter $\gamma_{h}$ : productivity is distributed over $[1,+\infty)$ according to

$$
P\left(\tilde{\varphi}_{h}<\varphi\right)=G_{h}(\varphi)=1-\varphi^{-\gamma_{h}}
$$

with $\gamma_{h}>\sigma_{h}-1$. An inverse measure of the heterogeneity in sector $h$ is given by $\gamma_{h}$. Sectors with a high $\gamma$ are more homogenous, in the sense that more output is concentrated among the smallest and least productive firms. ${ }^{6}$ The assumption that productivity shocks are Pareto distributed is made first for analytical tractability, and second because it provides a good approximation of the distribution of firm sizes in the United States. ${ }^{7}$

I assume that the total mass of potential entrants in country $n$ in each differentiated sector is proportional to $w_{n} L_{n}$, so that larger and wealthier countries have more entrants. This assumption greatly simplifies the analysis. It is similar to Eaton and Kortum (2002), where the set of goods is exogenously given. Since I do not impose free entry, firms generate net profits that have to be redistributed. I assume that each worker owns $w_{n}$ shares of a global fund. The fund collects profits from all firms and redistributes them in units of the numeraire good to its shareholders.

Demand for Differentiated Goods. - The total income spent by workers in country $j, Y_{j}$, is the sum of their labor income $\left(w_{j} L_{j}\right)$ and of the dividends they get from their portfolio $\left(w_{j} L_{j} \pi\right)$, where $\pi$ is the dividend per share of the global mutual fund. Given the optimal pricing of firms,

\footnotetext{
${ }^{4}$ As long as the share of the homogenous good, $\mu_{0}$, is large enough, or trade barriers in the other sectors are large enough, this condition will hold.

${ }^{5} \tau_{i j}^{h}>1$ for any $i \neq j$ and $\tau_{i i}^{h}=1$. I also impose a triangular inequality to prevent transportation arbitrages: $\forall(i, j, k)$, $\tau_{i k} \leq \tau_{i j} \times \tau_{j k}$.

${ }^{6} \ln \varphi$ has a standard deviation equal to $1 / \gamma$. The assumption $\gamma>\sigma-1$ ensures that, in equilibrium, the size distribution of firms has a finite mean.

${ }^{7}$ See Luttmer (2002) for the most recent evidence.
} 
and the demand by consumers, exports from country $i$ to country $j$ in sector $h$, by a firm with a labor productivity $\varphi$, are

$$
x_{i j}^{h}(\varphi)=p_{i j}^{h}(\varphi) q_{i j}^{h}(\varphi)=\mu_{h} Y_{j}\left(\frac{p_{i j}^{h}(\varphi)}{P_{j}^{h}}\right)^{1-\sigma_{h}},
$$

where $P_{j}^{h}$ is the ideal price index for good $h$ in country $j$. If only those firms above the productivity threshold $\bar{\varphi}_{k j}^{h}$ in country $k$ and sector $h$ export to country $j$, the ideal price index for good $h$ in country $j, P_{j}$, and dividends per share, $\pi$, are defined as

$$
\begin{gathered}
P_{j}^{h}=\left(\sum_{k=1}^{N} w_{k} L_{k} \int_{\bar{\varphi}_{k j}^{h}}^{\infty}\left(\frac{\sigma_{h}}{\sigma_{h}-1} \frac{w_{k} \tau_{k j}^{h}}{\varphi}\right)^{1-\sigma_{h}} d G_{h}(\varphi)\right)^{1 /\left(1-\sigma_{h}\right)} ; \\
\pi=\frac{\sum_{h=1}^{H} \sum_{k, l=1}^{N} w_{k} L_{k}\left(\int_{\bar{\varphi}_{k l}^{h}}^{\infty} \pi_{k l}^{h}(\varphi) d G_{h}(\varphi)\right)}{\sum_{n=1}^{N} w_{n} L_{n}}
\end{gathered}
$$

where $\pi_{k l}^{h}(\varphi)=\left(p_{k l}^{h}(\varphi)-c_{k l}^{h}(\varphi)\right) q_{k l}^{h}(\varphi)-f_{k l}^{h}$ are the net profits that a firm with productivity $\varphi$ in country $k$ and sector $h$ earns from exporting to country $l$.

For now, I will consider only sector $h$. The other sectors are analogous. For notational clarity, I drop the $h$ subscript and all sectoral variables will refer to sector $h$ when there is no ambiguity.

\section{Trade with Heterogeneous Firms}

In this section, I compute the global equilibrium of this world economy. To do so, I solve for the selection of firms into different export markets. I generate predictions for aggregate bilateral trade flows.

A firm chooses a subset of countries where it sells its output, and sets prices for its good in each market, taking the strategies of other firms and of consumers as given. Consumers chose the quantity consumed of each variety available domestically, given prices. All agents move simultaneously, and an equilibrium is a fixed point to their strategies. Firms decide whether to enter a given market depending on how much competition they expect to face in that market. The toughness of competition in turn depends on which firms enter. I derive the solution to this selection problem, which turns out to be quite tractable.

Productivity Threshold.-Less productive firms are not able to generate enough profits abroad to cover the fixed cost of entering foreign markets. Exporters are therefore only a subset of domestic firms. This subset varies with the characteristics of the foreign market. The profits firm $\varphi$ earns when exporting from $i$ to $j$ are $\pi_{i j}(\varphi)=\mu / \sigma Y_{j}\left[\sigma /(\sigma-1)\left(w_{i} \tau_{i j} / \varphi\right) / P_{j}\right]^{1-\sigma}-f_{i j}$. Define the threshold $\bar{\varphi}_{i j}$ from $\pi_{i j}\left(\bar{\varphi}_{i j}\right)=0$ as the productivity of the least productive firm in country $i$ able to export to country $j$ :

$$
\bar{\varphi}_{i j}=\lambda_{1}\left(\frac{f_{i j}}{Y_{j}}\right)^{1 /(\sigma-1)} \frac{w_{i} \tau_{i j}}{P_{j}},
$$

with $\lambda_{1}$ a constant. ${ }^{8}$ I assume that trade barriers are always high enough so that $\forall k, l, \bar{\varphi}_{k l}>1$.

$$
{ }^{8} \lambda_{1}=(\sigma / \mu)^{1 /(\sigma-1)}(\sigma /(\sigma-1))
$$


Equilibrium Price Indices.-Until now, I have considered aggregate prices as given. They do adjust, however, depending on country characteristics. Thanks to two simplifying assumptions-wages are exogenously pinned down in the homogenous sector, and the number of potential entrants (not the number of actual entrants) is exogenously given - the set of firms that export to country $j$ depends only on country $j$ 's characteristics. Plugging the productivity thresholds from equation (7) into the price index from equation (5), I can solve for the equilibrium price index:

$$
P_{j}=\lambda_{2} \times Y_{j}^{1 / \gamma-1 /(\sigma-1)} \times \theta_{j}
$$

where $\theta_{j}^{-\gamma} \equiv \sum_{k=1}^{N}\left(Y_{k} / Y\right) \times\left(w_{k} \tau_{k j}\right)^{-\gamma} \times f_{k j}^{-[\gamma /(\sigma-1)-1]}, Y$ is world output, and $\lambda_{2}$ is a constant. ${ }^{9}$

An aggregate index of $j$ 's remoteness from the rest of the world is given by $\theta_{j} \cdot{ }^{10}$ It is reminiscent of the "multilateral resistance variable" introduced by Anderson and Eric Van Wincoop (2003). In addition to their measure, it takes into account the impact of fixed costs and of firm heterogeneity on aggregate prices.

Equilibrium Exports, Thresholds, and Profits.-Exports by an individual firm depend on its productivity, the trade barriers it must overcome, aggregate demand, the set of competitors it is facing, and the price they set. Plugging the general equilibrium price index from equation (8) into the demand function, and into the productivity threshold from equation (7), I can solve simultaneously for firm level exports the productivity thresholds and total world profits. In general equilibrium, exports $x_{i j}(\varphi)$ from country $i$ to country $j$ by an individual firm with productivity $\varphi$, the productivity threshold $\bar{\varphi}_{i j}$ above which firms in $i$ export to $j$, aggregate output $Y_{j}$, and dividends per share $\pi$, are given by

$$
\left\{\begin{aligned}
x_{i j}(\varphi) & =\left\{\begin{array}{l}
\lambda_{3} \times\left(\frac{Y_{j}}{Y}\right)^{(\sigma-1) / \gamma} \times\left(\frac{\theta_{j}}{w_{i} \tau_{i j}}\right)^{\sigma-1} \times \varphi^{\sigma-1}, \text { if } \varphi \geq \bar{\varphi}_{i j} \\
0 \text { otherwise, }
\end{array}\right. \\
\bar{\varphi}_{i j} & =\lambda_{4} \times\left(\frac{Y}{Y_{j}}\right)^{1 / \gamma} \times\left(\frac{w_{i} \tau_{i j}}{\theta_{j}}\right) \times f_{i j}^{1 /(\sigma-1)}, \\
Y_{i} & =\left(1+\lambda_{5}\right) \times w_{i} L_{i}, \\
\pi & =\lambda_{5},
\end{aligned}\right.
$$

9

$$
\lambda_{2}^{\gamma}=\left(\frac{\gamma-(\sigma-1)}{\gamma}\right)\left(\frac{\sigma}{\mu}\right)^{\gamma /(\sigma-1)-1}\left(\frac{\sigma}{\sigma-1}\right)^{\gamma}\left(\frac{1+\pi}{Y}\right) .
$$

Note that there is a slight abuse of notations, as dividends per share $(\pi)$ and world output $(\mathrm{Y})$ will be endogenously determined in equilibrium. However, firms as well as consumers take total world profits and output as a constant. I will solve for $(\pi, Y)$ in equilibrium.

${ }^{10} \mathrm{~A}$ simple way to interpret this aggregate index is to look at a symmetrical case: when $w_{k} \tau_{k j}=w \tau_{j}$ and $f_{k j}=f_{j}$ for all $k$ 's, $\theta_{j}=f_{j}^{1 /(\sigma-1)-1 / \gamma} \times w \tau_{j}$. In asymmetric cases, $\theta_{j}$ is a weighted average of bilateral trade barriers. 
with $\lambda_{3}, \lambda_{4}$, and $\lambda_{5}$ as constants. ${ }^{11}$ Equilibrium variables are functions of fundamentals only: the size $L_{j},{ }^{12}$ the productivity $w_{i}$, the trade barriers $f_{i j}$ and $\tau_{i j}$, and the measure of $j$ 's remoteness from the rest of the world, $\theta_{j}$.

As expected from this simple monopolistic competition model, exports by individual firms depend on the transportation $\operatorname{cost} \tau_{i j}$ with an elasticity $\sigma-1$. Firm-level trade is very similar to what a traditional model of trade with representative firms would predict for aggregate bilateral trade flows. In contrast, because of the selection of firms into the export market, aggregate bilateral trade in the present model will look radically different.

PROPOSITION 1 (Aggregate Trade): Total exports (f.o.b.) $X_{i j}^{h}$ in sector $h$ from country $i$ to country $j$ are given by

$$
X_{i j}^{h}=\mu_{h} \times \frac{Y_{i} \times Y_{j}}{Y} \times\left(\frac{w_{i} \tau_{i j}^{h}}{\theta_{j}^{h}}\right)^{-\gamma_{h}} \times\left(f_{i j}^{h}\right)^{-\left[\gamma_{h} /\left(\sigma_{h}-1\right)-1\right]} .
$$

Exports are a function of country sizes $\left(Y_{i}\right.$ and $\left.Y_{j}\right),{ }^{13}$ workers' productivity $\left(w_{i}\right)$, the bilateral trade costs, variable $\left(\tau_{i j}^{h}\right)$ and fixed $\left(f_{i j}^{h}\right)$, and the measure of $j$ 's remoteness from the rest of the $\operatorname{world}\left(\theta_{j}^{h}\right) .{ }^{14}$

\section{PROOF:}

See the Appendix.

The gravity structure of trade has been dramatically distorted by the presence of firm heterogeneity.

First note that the elasticity of exports with respect to variable trade barriers, $\gamma$, is larger than in the absence of firm heterogeneity, and larger than the elasticity for each individual firm (both equal to $\sigma-1$ ). A reduction in variable costs not only causes an increase in the size of exports of each exporter, but also allows some new firms to enter. The extensive margin comes on top of the intensive margin and amplifies the impact of variable costs. This amplification effect is quantitatively important. Anderson and Van Wincoop (2004) argue that if one assumes that trade is governed by an underlying model of trade with identical firms, trade barriers between the United States and Canada must be equivalent to a 46 percent tariff in order to explain the observed bilateral trade flows (for a benchmark case with $\sigma=8$ ). In the presence of firm heterogeneity,

$$
\begin{aligned}
{ }^{11} \lambda_{3}=\sigma \lambda_{4}^{1-\sigma}, \lambda_{4}=\left[\sigma / \mu \times \gamma /[\gamma-(\sigma-1)] \times 1 /\left(1+\lambda_{5}\right)\right]^{1 / \gamma}, \text { and } \\
\lambda_{5}=\frac{\sum_{h=1}^{H}\left(\frac{\sigma_{h}-1}{\gamma_{h}}\right) \frac{\mu_{h}}{\sigma_{h}}}{1-\sum_{h=1}^{H}\left(\frac{\sigma_{h}-1}{\gamma_{h}}\right) \frac{\mu_{h}}{\sigma_{h}}} .
\end{aligned}
$$

I am grateful to Sebastian Krautheim for helpful suggestions on computing aggregate profits.

${ }^{12}$ The elasticity of individual firms' exports with respect to the destination market $Y_{j}$ is less than one. This is due to the impact of market size on the degree of price competition: as the size of the market grows, more firms enter, which eat up part of the market shares of existing exporters.

${ }^{13} \mathrm{GDP}$ is proportional to labor income: $Y_{i}=\left(1+\lambda_{5}\right) w_{i} L_{i}$.

${ }^{14}$ Note that the ratio of $i$ 's market share in $k$, and $j$ 's market share in $k$, depends only on the ratio of $i$ 's trade barriers and $j$ 's trade barriers. If I define the composite measure of trade barriers $\kappa_{i k}=\left(w_{i} \tau_{i k}\right)^{-\gamma} \times f_{i k}^{-[\gamma-(\sigma-1)] /(\sigma-1)}$, I get: $\left(X_{i k} / Y_{i}\right) /\left(X_{j k} / Y_{j}\right)=\kappa_{i k} / \kappa_{j k}$. Similarly, $i$ 's market share in $k$ depends only on trade barriers from $i$ relative to trade barriers from other countries: $X_{i k} / X_{k}=\left[\left(L_{i} / L\right) \kappa_{i k} / \sum_{j}\left(L_{j} / L\right) \kappa_{j k}\right]$. 
and using a heterogeneity parameter estimated from firm-level data $(\gamma /(\sigma-1) \approx 2),{ }^{15}$ I would infer from the same trade volume data that trade barriers are equivalent to a 21 percent tariff $(1.21=\sqrt{1.46}) \cdot{ }^{16}$ This is far below their 46 percent estimate.

Second, the elasticity of exports with respect to transportation costs depends on the degree of firm heterogeneity, $\gamma$. In more homogenous sectors ( $\gamma$ high), large productive firms represent a smaller fraction of firms. The productivity threshold moves in a region where most of the mass of firms lies. In those sectors, aggregate exports are sensitive to changes in transportation costs because many firms exit and enter when variable costs fluctuate.

Third and most important, the elasticity of exports with respect to variable costs does not depend at all on the elasticity of substitution between goods, $\sigma,{ }^{17}$ and the elasticity of exports with respect to fixed costs is negatively related to the elasticity $\sigma$. This prediction is in stark contrast with models with representative firms. In such models, the elasticity of exports with respect to transportation costs would be equal to $\sigma-1$.

\section{Intensive versus Extensive Margins of Trade}

In this section, I describe how the elasticity of substitution magnifies the sensitivity of the intensive margin to trade barriers and dampens the sensitivity of the extensive margin. I prove that the dampening effect on the extensive margin dominates the magnifying effect on the intensive margin.

Thus far, I have shown that in the presence of firm heterogeneity, the selection of firms into the export market becomes a key feature of the adjustment of trade flows. The main prediction of the model is that the extensive margin and the intensive margin are affected in opposite directions by the elasticity of substitution. If the elasticity of substitution is high, then the impact of trade barriers is strong on the intensive margin and mild on the extensive margin. The reverse holds true when the elasticity of substitution is low. The dampening effect of the elasticity of substitution on the extensive margin dominates the magnifying effect on the intensive margin.

PROPOSITION 2 (Intensive and Extensive Margins): The elasticity of substitution ( $\sigma$ ) has no effect on the elasticity of trade flows with respect to variable trade costs $(\zeta)$, and a negative effect on the elasticity of trade flows with respect to fixed costs $(\xi)$ :

$$
\text { if } \zeta \equiv-\frac{d \ln X_{i j}}{d \ln \tau_{i j}} \text { and } \xi \equiv-\frac{d \ln X_{i j}}{d \ln f_{i j}} \text {, then } \frac{\partial \zeta}{\partial \sigma}=0 \text { and } \frac{\partial \zeta}{\partial \sigma}<0
$$

\footnotetext{
${ }^{15}$ I measure $\gamma /(\sigma-1)$ as the regression coefficient of the log of rank (ordering US firms according to their sales in the United States) on the log of sales, using Compustat data on US listed firms. With an alternative method using the propensity of French firms to export to multiple markets, Eaton, Kortum, and Kramarz (2007) find a smaller number, $\gamma /(\sigma-1) \approx 1.5$.

${ }^{16}$ To make the two models comparable, despite the presence of fixed entry costs, I assume the entry cost into any Canadian province is the same for US and Canadian firms.

${ }^{17}$ Eaton and Kortum (2002) derive a similar prediction from a different setup. In a Ricardian model of trade, they find that bilateral trade flows do not depend on the elasticity of substitution between goods, but only on the scaling parameter of the underlying distribution of productivity shocks. They use Fréchet distributions, which approach Pareto distributions in their right tails: the distribution for shocks they consider is $1-F(z)=1-e^{-T z^{-\theta}}=T z^{-\theta}+o\left(z^{-\theta}\right)$. In equilibrium, they predict that the elasticity of trade flows with respect to trade barriers (variable only) is equal to $\theta$.
} 
PROOF:

To prove this proposition, I introduce formally the intensive and the extensive margins of trade. I describe the adjustment of each margin, and the sensitivity of these adjustments to the elasticity of substitution.

The impact of trade barriers, both variable and fixed, on aggregate trade flows can be decomposed into two different margins. The intensive margin is defined by how much each existing exporter changes the size of its exports. The extensive margin is defined by how much new entrants export (in the case of a reduction in trade barriers).

Differentiating the expression for aggregate exports, $X_{i j}=w_{i} L_{i} \int_{\bar{\varphi}_{i j}}^{\infty} x_{i j}(\varphi) d G(\varphi)$, I get the following expressions for each margin: ${ }^{18}$

$$
\begin{aligned}
d X_{i j} & =\left(w_{i} L_{i} \int_{\bar{\varphi}_{i j}}^{\infty} \frac{\partial x_{i j}(\varphi)}{\partial \tau_{i j}} d G(\varphi)\right) d \tau_{i j}-\left(w_{i} L_{i} x\left(\bar{\varphi}_{i j}\right) G^{\prime}\left(\bar{\varphi}_{i j}\right) \times \frac{\partial \bar{\varphi}_{i j}}{\partial \tau_{i j}}\right) d \tau_{i j} \\
& +\underbrace{\left(w_{i} L_{i} \int_{\bar{\varphi}_{i j}}^{\infty} \frac{\partial x_{i j}(\varphi)}{\partial f_{i j}} d G(\varphi)\right)}_{\text {Intensive margin }} d f_{i j}-\underbrace{\left(w_{i} L_{i} x\left(\bar{\varphi}_{i j}\right) G^{\prime}\left(\bar{\varphi}_{i j}\right) \times \frac{\partial \bar{\varphi}_{i j}}{\partial f_{i j}}\right)}_{\text {Extensive margin }} d f_{i j} .
\end{aligned}
$$

Following a reduction of trade barriers, each existing exporter $\left(\varphi>\bar{\varphi}_{i j}\right)$ exports more. This is the intensive margin. At the same time, higher potential profits attract new entrants $\left(\bar{\varphi}_{i j}\right.$ goes down $)$. This is the extensive margin.

In elasticity notations, I get the following expression for each margin for changes in the variable cost, $\tau_{i j}:{ }^{19}$

$$
\zeta \equiv-\frac{d \ln X_{i j}}{d \ln \tau_{i j}}=\underbrace{(\sigma-1)}_{\begin{array}{c}
\text { Intensive margin } \\
\text { Elasticity }
\end{array}}+\underbrace{(\gamma-(\sigma-1))}_{\begin{array}{c}
\text { Extensive margin } \\
\text { Elasticity }
\end{array}}=\gamma .
$$

When variable costs move $(\sigma-1$ increases with $\sigma), \sigma$ magnifies the intensive margin, whereas it dampens the extensive margin $(\gamma-(\sigma-1)$ decreases with $\sigma) .{ }^{20}$ The effect of $\sigma$ on each margin cancels out, so that

$$
\frac{\partial \zeta}{\partial \sigma}=0
$$

\footnotetext{
${ }^{18}$ I use Leibniz rule to separate the intensive from the extensive margin. I apply Lebesgue's monotone convergence theorem to ensure the existence of, and to compute, the intensive margin.

${ }^{19}$ See the Appendix for a complete derivation.

${ }^{20} \mathrm{I}$ have implicitly assumed that changes in both $\tau_{i j}$ and $f_{i j}$ have no significant impact on the general equilibrium. That is, I have assumed that $\partial \theta_{j} / \partial \tau_{i j}=\partial \theta_{j} / \partial f_{i j}=0$. This is a fair approximation as long as country $i$ is not too large compared to the rest of the world $\left(Y_{i} / Y\right.$ small). Relaxing this assumption would reinforce my results, but it would make calculations cumbersome. See the Technical Appendix (available at http://www.aeaweb.org/articles.php?doi=10.1257/ aer.98.4.1707 for a derivation of the general case.
} 
In elasticity notation, I get the following expression for each margin for changes in the fixed costs, $f_{i j}$ :

$$
\xi \equiv-\frac{d \ln X_{i j}}{d \ln f_{i j}}=\underbrace{0}_{\begin{array}{c}
\text { Intensive margin } \\
\text { Elasticity }
\end{array}}+\underbrace{\frac{\gamma}{\sigma-1}-1}_{\begin{array}{c}
\text { Extensive margin } \\
\text { Elasticity }
\end{array}}=\frac{\gamma}{\sigma-1}-1 .
$$

When only fixed costs move, $\sigma$ has no impact on the intensive margin, whereas it dampens the impact on the extensive margin $(\gamma /(\sigma-1)-1$ decreases with $\sigma)$. The impact of $\sigma$ on the elasticity of trade flows with respect to fixed costs is always negative:

$$
\frac{\partial \xi}{\partial \sigma}<0
$$

The intuition for these results is the following. When goods are highly differentiated ( $\sigma$ is low), the demand for each individual variety is relatively insensitive to changes in trade costs. In other words, when $\sigma$ is low, trade barriers have little impact on the intensive margin of trade. This margin is the only one in the Krugman model of trade with representative firms.

The interaction between the elasticity of substitution and the extensive margin is more complex. When $\sigma$ is low, the market share that each firm is able to capture is relatively insensitive to differences in productivity. Less productive firms are still able to capture a relatively large market share, despite having to charge a higher price than other firms. As trade barriers decrease, some firms with a low level of productivity are able to enter. When goods are highly differentiated ( $\sigma$ is low), these new entrants are relatively large compared to the firms that are already exporting. Therefore, the extensive margin is strongly affected by trade barriers when $\sigma$ is low. The reverse holds when $\sigma$ is high.

In this section, I have explained why the elasticity of substitution has opposite effects on the intensive and the extensive margins of trade. A higher elasticity of substitution makes the intensive margin more sensitive to changes in trade barriers, whereas it makes the extensive margin less sensitive. What is the net impact of $\sigma$ on the two margins? I prove in Proposition 2 that with Pareto distributed productivity shocks, the extensive margin always dominates. Contrary to the predictions of the Krugman model with representative firms, the elasticity of substitution $\sigma$ always dampens the impact of trade barriers on trade flows.

\section{Conclusion}

Introducing firm heterogeneity leaves many of the predictions of the Krugman (1980) model of international trade unaffected. Most important, the gravity structure of bilateral trade flows is preserved. In this paper, I have identified a key difference between the Krugman model with representative firms and a model with firm heterogeneity. The impact of trade barriers is dampened by the elasticity of substitution, and not magnified by it. I introduce fixed export costs and adjustments on the extensive margin in a simple model of international trade. A high elasticity of substitution translates productivity differences into large differences in size. As firm sizes get more dispersed, fixed costs have a lesser impact on exports: large firms can easily overcome those fixed costs. Aggregate trade flows are less sensitive to trade barriers when goods are more substitutable. 
PROPOSITION 1 (Reminded): Total exports (f.o.b.) $X_{i j}^{h}$ in sector $h$ from country $i$ to country $j$ are given by

$$
X_{i j}^{h}=\mu_{h} \times \frac{Y_{i} \times Y_{j}}{Y} \times\left(\frac{w_{i} \tau_{i j}^{h}}{\theta_{j}^{h}}\right)^{-\gamma_{h}} \times\left(f_{i j}^{h}\right)^{-\left(\gamma_{h} /\left(\sigma_{h}-1\right)-1\right)} .
$$

Exports are a function of country sizes $\left(Y_{i}\right.$ and $\left.Y_{j}\right)$, workers' productivity $\left(w_{i}\right)$, the bilateral trade costs, variable $\left(\tau_{i j}^{h}\right)$ and fixed $\left(f_{i j}^{h}\right)$, and the measure of $j$ 's remoteness from the rest of the $\operatorname{world}\left(\theta_{j}^{h}\right)$.

\section{PROOF:}

Aggregate exports from $i$ to $j$ are defined as the sum of export of each individual firm with productivity $\varphi \geq \bar{\varphi}_{i j}^{h}$ :

$$
X_{i j}^{h}=w_{i} L_{i} \int_{\bar{\varphi}_{i j}^{h}}^{\infty} x_{i j}^{h}(\varphi) d G_{h}(\varphi) .
$$

From equation (9) we know the size of firm-level exports $x_{i j}^{h}\left(\varphi \mid \varphi \geq \bar{\varphi}_{i j}^{h}\right)$ and the productivity threshold $\bar{\varphi}_{i j}^{h}$. Using the specific assumption about the distribution $G_{h}$ of productivity shocks from equation (3), we can rewrite aggregate exports as

$$
\begin{gathered}
X_{i j}^{h}=w_{i} L_{i} \int_{\bar{\varphi}_{i j}^{h}}^{\infty} \lambda_{3}^{h} \times\left(\frac{Y_{j}}{Y}\right)^{(\sigma-1) / \gamma} \times\left(\frac{\theta_{j}^{h}}{w_{i} \tau_{i j}^{h}}\right)^{\sigma-1} \times \varphi^{\sigma_{h}-1} \times \frac{\varphi^{-\gamma_{h}-1}}{\gamma_{h}} d \varphi, \\
\text { with } \bar{\varphi}_{i j}^{h}=\lambda_{4}^{h} \times\left(\frac{Y}{Y_{j}}\right)^{1 / \gamma} \times\left(\frac{w_{i} \tau_{i j}^{h}}{\theta_{j}^{h}}\right) \times f_{i j}^{h(1 /(\sigma-1))},
\end{gathered}
$$

where $\lambda_{3}^{h}$ and $\lambda_{4}^{h}$ are some constants. ${ }^{21}$ Given the assumption of Pareto distributed productivity and isoelastic preferences, we get a simple solution for the integral. After solving the integral and rearranging, we get

$$
X_{i j}^{h}=\lambda_{h} \times \frac{w_{i} L_{i} Y_{j}}{Y} \times\left(\frac{w_{i} \tau_{i j}^{h}}{\theta_{j}^{h}}\right)^{-\gamma_{h}} \times\left(f_{i j}^{h}\right)^{-\left(\gamma_{h} /\left(\sigma_{h}-1\right)-1\right)},
$$

with $\lambda_{h}=\left(1+\lambda_{5}\right) \times \mu_{h}$. Noting that $Y_{i}=\left(1+\lambda_{5}\right) w_{i} L_{i}$, we get

$$
X_{i j}^{h}=\mu_{h} \times \frac{Y_{i} \times Y_{j}}{Y} \times\left(\frac{w_{i} \tau_{i j}^{h}}{\theta_{j}^{h}}\right)^{-\gamma_{h}} \times\left(f_{i j}^{h}\right)^{-\left(\gamma_{h} /\left(\sigma_{h}-1\right)-1\right)} .
$$

PROPOSITION 2 (Reminded):

(i) The elasticity of the intensive margin of trade with respect to variable trade costs is $(\sigma-1)$.

(ii) The elasticity of the extensive margin of trade with respect to variable costs is $(\gamma-$ $(\sigma-1))$.

${ }^{21} \lambda_{3}^{h}=\sigma\left(\lambda_{4}^{h}\right)^{1-\sigma}, \lambda_{4}^{h}=\left[\sigma_{h} / \mu_{h} \times \gamma_{h} /\left(\gamma_{h}-\left(\sigma_{h}-1\right)\right) \times 1 /\left(1+\lambda_{5}\right)\right]^{1 / \gamma_{h}}$, and $\lambda_{5}=\left\{\left[\sum_{h=1}^{H}\left(\left(\sigma_{h}-1\right) / \gamma_{h}\right)\left(\mu_{h} / \sigma_{h}\right)\right] /\right.$ $\left.\left[1-\sum_{h=1}^{H}\left(\left(\sigma_{h}-1\right) / \gamma_{h}\right)\left(\mu_{h} / \sigma_{h}\right)\right]\right\}$. 
(iii) The elasticity of the intensive margin of trade with respect to fixed costs is 0.

(iv) The elasticity of the extensive margin of trade with respect to fixed costs is $[\gamma-$ $(\sigma-1)] /(\sigma-1)$.

\section{PROOF:}

(i) The definition of the intensive and the extensive margins from Proposition 2 gives us

$$
\begin{gathered}
-\frac{d \ln X_{i j}}{d \ln \tau_{i j}}=\frac{-d X_{i j} / d \tau_{i j}}{X_{i j} / \tau_{i j}}=\underbrace{-\frac{\tau_{i j}}{X_{i j}}\left(w_{i} L_{i} \int_{\bar{\varphi}_{i j}}^{\infty} \frac{\partial x_{i j}(\varphi)}{\partial \tau_{i j}} d G(\varphi)\right)}_{\text {Intensive margin elasticity }}+\underbrace{\frac{\tau_{i j}}{X_{i j}}\left(w_{i} L_{i} x\left(\bar{\varphi}_{i j}\right) G^{\prime}\left(\bar{\varphi}_{i j}\right) \times \frac{\partial \bar{\varphi}_{i j}}{\partial \tau_{i j}}\right)}_{\text {Extensive margin elasticity }} . \\
-\frac{d \ln X_{i j}}{d \ln f_{i j}}=\frac{-d X_{i j} / d f_{i j}}{X_{i j} / f_{i j}}=\underbrace{-\frac{f_{i j}}{X_{i j}}\left(w_{i} L_{i} \int_{\bar{\varphi}_{i j}}^{\infty} \frac{\partial x_{i j}(\varphi)}{\partial f_{i j}} d G(\varphi)\right)}_{\text {Intensive margin elasticity }}+\underbrace{\frac{f_{i j}}{X_{i j}}\left(w_{i} L_{i} x\left(\bar{\varphi}_{i j}\right) G^{\prime}\left(\bar{\varphi}_{i j}\right) \times \frac{\partial \bar{\varphi}_{i j}}{\partial f_{i j}}\right)}_{\text {Extensive margin elasticity }} .
\end{gathered}
$$

Using the definition of equilibrium individual exports from equation (9), and assuming that country $i$ is small enough and/or remote enough, so that $\partial \theta_{j} / \partial \tau_{i j}=-\gamma\left(Y_{i} / Y\right) \times w_{i}^{-\gamma} \tau_{i j}^{-\gamma-1} \times$ $f_{i j}^{-[\gamma-(\sigma-1)] /(\sigma-1)} \approx 0$, we get

$$
\frac{\partial x_{i j}(\varphi)}{\partial \tau_{i j}}=-(\sigma-1) \frac{x_{i j}(\varphi)}{\tau_{i j}}
$$

Integrating over all exporters, we get

$$
\begin{aligned}
& \begin{aligned}
\text { Elasticity of the intensive margin } \\
\text { with respect to variable costs }
\end{aligned}=-\frac{\tau_{i j}}{X_{i j}}\left(w_{i} L_{i} \int_{\bar{\varphi}_{i j}}^{\infty} \frac{\partial x_{i j}(\varphi)}{\partial \tau_{i j}} d G(\varphi)\right) \\
& =(\sigma-1) \frac{\tau_{i j}}{X_{i j}} \frac{w_{i} L_{i} \int_{\bar{\varphi}_{i j}}^{\infty} x_{i j}(\varphi) d G(\varphi)}{\tau_{i j}} \\
& =(\sigma-1) \frac{\tau_{i j}}{X_{i j}} \frac{X_{i j}}{\tau_{i j}} \\
& =(\sigma-1) .
\end{aligned}
$$

(ii) Using the definition of the equilibrium productivity threshold from equation (9), we get

$$
\frac{\partial \bar{\varphi}_{i j}}{\partial \tau_{i j}}=\frac{\bar{\varphi}_{i j}}{\tau_{i j}} .
$$


Using the definition of firm-level exports $x_{i j}(\varphi)=\lambda_{i j} \varphi^{\sigma-1}$ from equation (9), and the definition of the distribution of productivity shocks $G^{\prime}(\varphi)=\varphi^{-\gamma-1} / \gamma$ from equation (3), we can rewrite aggregate exports in the following way:

$$
\begin{aligned}
X_{i j} & =w_{i} L_{i} \int_{\bar{\varphi}_{i j}^{h}}^{\infty} x_{i j}(\varphi) d G(\varphi) \\
& =w_{i} L_{i} \int_{\bar{\varphi}_{i j}}^{\infty} \lambda_{i j} \varphi^{\sigma-1} \frac{\varphi^{-\gamma-1}}{\gamma} d \varphi \\
& =\frac{1}{(\gamma-(\sigma-1)) \gamma} w_{i} L_{i} \lambda_{i j}^{\sigma-1} \bar{\varphi}_{i j}^{(\sigma-1)-\gamma} \\
& =\frac{1}{\gamma-(\sigma-1)} \times w_{i} L_{i} x_{i j}\left(\bar{\varphi}_{i j}\right) G^{\prime}\left(\bar{\varphi}_{i j}\right) \times \bar{\varphi}_{i j} .
\end{aligned}
$$

We therefore get the simple solution for the elasticity:

$$
\begin{aligned}
& \begin{aligned}
& \text { Elasticity of the extensive margin } \\
& \text { with respect to variable costs }=\frac{\tau_{i j}}{X_{i j}}\left(w_{i} L_{i} x\left(\bar{\varphi}_{i j}\right) G^{\prime}\left(\bar{\varphi}_{i j}\right) \times \frac{\partial \bar{\varphi}_{i j}}{\partial \tau_{i j}}\right) \\
&=\frac{\tau_{i j}}{X_{i j}}\left(\frac{w_{i} L_{i} x\left(\bar{\varphi}_{i j}\right) G^{\prime}\left(\bar{\varphi}_{i j}\right) \times \bar{\varphi}_{i j}}{\tau_{i j}}\right) \\
&=(\gamma-(\sigma-1)) \frac{\tau_{i j}}{X_{i j}} \frac{X_{i j}}{\tau_{i j}} \\
&=(\gamma-(\sigma-1)) .
\end{aligned}
\end{aligned}
$$

(iii) Using the definition of the equilibrium firm-level exports from equation (9), we get

$$
\frac{\partial x_{i j}(\varphi)}{\partial f_{i j}}=0 .
$$

We directly derive that the elasticity of the intensive margin of trade with respect to fixed costs is 0 .

(iv) Using the definition of the equilibrium productivity threshold from equation (9), we get

$$
\frac{\partial \bar{\varphi}_{i j}}{\partial f_{i j}}=\frac{1}{\sigma-1} \times \frac{\bar{\varphi}_{i j}}{f_{i j}},
$$

and using the same procedure as in $(i i)$, we prove that the elasticity of the extensive margin with respect to fixed trade costs is $\gamma /(\sigma-1)-1$. 


\section{REFERENCES}

Anderson, James E. 1979. "A Theoretical Foundation for the Gravity Equation." American Economic Review, 69(1): 106-16.

Anderson, James E., and Eric van Wincoop. 2003. "Gravity with Gravitas: A Solution to the Border Puzzle." American Economic Review, 93(1): 170-92.

Anderson, James E., and Eric van Wincoop. 2004. "Trade Costs." Journal of Economic Literature, 42(3): 691-751.

Andersson, Martin. 2007. "Entry Costs and Adjustments on the Extensive Margin—An Analysis of How Familiarity Breeds Exports." Unpublished.

Arkolakis, Costas. 2007. "Market Access Costs and the New Consumers Margin in International Trade." Unpublished.

Axtell, Robert L. 2001. “Zipf Distribution of U. S. Firm Sizes.” Science, 293(5536): 1818-20.

Crozet, Matthieu, and Pamina Koenig. 2007. "Structural Gravity Equation with Extensive and Intensive Margins." Unpublished.

Eaton, Jonathan, and Samuel Kortum. 2002. “Technology, Geography, and Trade.” Econometrica, 70(5): $1741-79$.

Eaton, Jonathan, Samuel Kortum, and Francis Kramarz. 2007. "An Anatomy of International Trade: Evidence from French Firms." Unpublished.

Gabaix, Xavier. 2008. "Power Laws." In The New Palgrave Dictionary of Economics. 2nd edition, ed. Steven N. Durlauf and Lawrence E. Blume. New York: Palgrave Macmillan.

Helpman, Elhanan, Marc J. Melitz, and Yona Rubinstein. Forthcoming. "Estimating Trade Flows: Trading Partners and Trading Volumes." Quarterly Journal of Economics.

Helpman, Elhanan, Marc J. Melitz, and Stephen R. Yeaple. 2004. "Export versus FDI with Heterogeneous Firms." American Economic Review, 94(1): 300-16.

Hummels, David, and Peter J. Klenow. 2005. "The Variety and Quality of a Nation's Exports." American Economic Review, 95(3): 704-23.

Koenig, Pamina. 2005. "The Intensive and Extensive Margins of Trade: Evidence from French Firms." Unpublished.

Krugman, Paul. 1980. "Scale Economies, Product Differentiation, and the Pattern of Trade." American Economic Review, 70(5): 950-59.

Luttmer, Erzo G. J. 2007. "Selection, Growth, and the Size Distribution of Firms." Quarterly Journal of Economics, 122(3): 1103-44.

Melitz, Marc J. 2003. "The Impact of Trade on Intra-Industry Reallocations and Aggregate Industry Productivity." Econometrica, 71(6): 1695-1725.

Obstfeld, Maurice, and Kenneth Rogoff. 2001. "The Six Major Puzzles in International Macroeconomics: Is There a Common Cause?" In NBER Macroeconomics Annual 2000, ed. Ben S. Bernanke and Kenneth Rogoff, 339-90. Cambridge, MA: MIT Press.

Rauch, James E. 1999. "Networks versus Markets in International Trade." Journal of International Economics, 48(1): 7-35.

Ruhl, Kim J. 2005. “The Elasticity Puzzle in International Economics.” Unpublished.

Simon, Herbert A., and Charles P. Bonini. 1958. "The Size Distribution of Business Firms." American Economic Review, 48(4): 607-17.

Yi, Kei-Mu. 2003. “Can Vertical Specialization Explain the Growth of World Trade?” Journal of Political Economy, 111(1): 52-102. 